how are we to account for the long dormant life of some organisms that possess a very small reserve of respirable material, as for example the spores of bacteria which in the dry state have a very long recorded life? Some refined experiment seems to be needed to try whether in such cases respiration, however infinitesimal, is not still going on.

This is not the only unsolved question that the dormancy of seeds presents. Every farmer and gardener is familiar with the growth of certain weeds, notably charlock, which follows the ploughing up of land which may have been in grass twenty or thirty years. But why in an ordinary arable field, subject to charlock, do we get a rush of growth in one year and few or no seedlings in another ? Why do other rare plants suddenly spring up in unexpected places ? In Dr. Brenchley's experiments on the germination of seeds contained in soils taken at different depths from the old Rothamsted plots, the soil samples are exposed to optimum conditions of aeration, moisture and temperature, but years elapso before all the seeds germinate.

In the past abnormal season many unexpected 'weeds' have appeared in the John Innes gardens. Some are comparatively uncommon plants, that as far as is known have never been grown here; for example, Datura sp., Ambrosia artemisiaefolia, Physalis edulis, etc. It may be supposed the seed had been introduced in manure, but considering the rarity of the plants, that only shifts the locality of the problem. One piece of land here, after it had been cleared from sweet peas, has covered itself with Nicotiana seedlings. Nine years earlier the plot had carried Nicotiana, but in the intervening period not a seedling had been seen. We know something of the effects of 'vernalisation' and of chilling in stimulating the germination of certain seeds which may otherwise refuse to start, but this dormancy of buried seeds still offers problems for experiment.

$$
\text { A. D. HALL. }
$$

John Innes Horticultural Institution, Merton, S.W.19.

\section{Kinetics of Photosynthesis}

I AM grateful to Emerson and Green ${ }^{1}$ for directing attention to the fact that the equation expressing the velocity of photosynthesis during the photostationary state $^{2}$ was incorrect because it indicated that the temperature coefficient is a function of the external $\mathrm{CO}_{2}$ concentration. Their alternative formula is open to the same criticism, since it indicates that the temperature coefficient increases with decrease in $\mathrm{CO}_{2}$ concentration. The error is due to an incomplete definition of the conditions which govern the photostationary state.

There are three processes involved; namely, the primary light reaction in which the chlorophyll in its complex with $\mathrm{CO}_{2}$ undergoes a change, the Blackman reaction in which this changed chlorophyll is restored to its original state, and the formation of the complex of chlorophyll with $\mathrm{CO}_{2}$. If the velocities of these three processes be equated to give the expression for the photostationary state, the resulting expression indicates that the rate of photosynthesis in flashing light is independent of the external $\mathrm{CO}_{2}$ concentration, which is known not to be the case. If, however, the assumption be made that the rate of formation of the complex with $\mathrm{CO}_{2}$ is very fast in the case of the chlorophyll formed in the Blackman reaction, and that the establishment of the equilibrium between ordinary chlorophyll and $\mathrm{CO}_{2}$ is slow, the equation for the photostationary state is simplified to

$y=k_{1} I(b A-x)=k_{2} x e^{-Q / R T}$

$\log \frac{y}{K-y}=\log \frac{k_{2}}{k_{1} I}-\frac{Q^{\prime}}{T}$,

where $A$ is the total concentration of chlorophyll in the irradiated surface, $b$ is the fraction which exists as the complex, $K=k_{1} I b A$ and $Q^{\prime}=Q / 2 \cdot 303 R$.

These equations indicate that the temperature coefficient is independent of the $\mathrm{CO}_{2}$ concentration and that the rate in flashing light is a direct function of the $\mathrm{CO}_{2}$ concentration, since $b$ is a function of that concentration.

Emerson and Green's equation for the photo. stationary state

$$
y=k_{1} I x=k_{2}(a-x) P e^{-Q / R T}
$$

appears to be incorrect. Since $k_{2}(a-x) P e^{-Q / R T}$ is the velocity of the dark or Blackman reaction, $x$ will be a maximum after a period of darkness. It follows that $k_{1} I x$ will be a maximum the moment irradiation is commenced and will decrease with time until the photostationary state has been established. The above equation, therefore, cannot express the photostationary state.

It is not possible here to discuss the chemistry of the photosynthetic process, but it may be stated that it is not intended to represent the Blackman reaction as being uni-molecular. It is bi-molecular, but since the concentration of the second reactant is assumed to be large and sensibly constant, it is included in the constant $k_{2}$. A complete account will be given in a separate communication.

Chemical Laboratories,

E. C. C. BALY.

University, Liverpool. Nov. 20.

${ }^{1}$ NATURE, 134, 289, August 25, 1934

2 Nature, 133, 414, March 17, 1934.

\section{Inhibitors of Catalase Reaction}

IT is well known that the activity of catalase is greatly inhibited by very small concentrations of potassium cyanide, hydrogen sulphide and especially hydroxylamine. To these reagents we can now add sodium azide $\left(\mathrm{NaN}_{3}\right)$ which also acts as a strong inhibitor of catalase.

In a recently published note, Sevag and Maiweg ${ }^{1}$ have announced the discovery of a new type of catalase poison belonging to the group of oximes. They have found, however, that these compounds when used freshly prepared have no poisoning properties. The inhibitory property of the oxime solution is manifested only after acidifying it with dilute hydrochloric acid, warming for twenty minutes and neutralising with dilute soda. It is interesting to note that this inhibitory property was found by these authors to be proportional to the strength of acid used in their manipulation.

Following the technique described by Sevag and Maiweg, $0.232 \mathrm{gm}$. of dimethylglyoxime $\left(\mathrm{CH}_{3} \mathrm{C}(\mathrm{NOH}) \cdot \mathrm{C}(\mathrm{NOH}) \cdot \mathrm{CH}_{3}\right)$ was dissolved in 100 c.c. of water, containing 10 c.c. normal hydrochloric acid, warmed for 20 minutes on a water bath and neutralised with normal caustic soda.

The solution thus prepared, contrary to the 